\title{
Operation of small isolated power system with large non-controllable RES penetration - System Operator's experience in EI Hierro Island
}

\author{
R. Corujo ${ }^{1}$, P. Santos ${ }^{1}$ and R. Ascanio ${ }^{1}$ \\ ${ }^{1}$ Isolated System Department \\ Red Eléctrica de España S.A.U. (REE) \\ Alcobendas, Madrid (Spain) \\ e-mail: rcorujo@ree.es, pasantos@ree.es, rascanio@ree.es
}

\begin{abstract}
The Canary Islands are facing a transition towards renewable energy, in an attempt to build a cleaner and cheaper power system for the coming years.

This transition poses a big challenge for the TSO that will face the operation of weak grids, with a large amount of noncontrollable generation, in a context of reduced natural inertia.
\end{abstract}

In this context the methodology and operational criteria of El Hierro's power system, operated by the TSO, are to maximize the amount of renewable energy in a safe way, minimizing the risks associated with the unpredictability of wind-power, and to do so minimizing the electrical power generation cost.

This paper shares the REE experience in the operation of a small isolated power system with large non-controllable RES that, as a result, has established a new record in 2018, where the the pumped storage hydro facility named Central Hidroeólica de El Hierro (CHE) covered the complete island's demand during 18 consecutive days, more than two weeks where the diesel power plant was completely off and the island was therefore $100 \%$ renewable.

\section{Key words}

Isolated systems, TSO, RES, storage, pumped hydro.

\section{Introduction}

Great challenges for the TSO has revealed in El Hierro Island, an isolated power system with several special characteristics:

First of all, it is a small system, both geographically and electrically. With 10,679 inhabitants and $268 \mathrm{~km}^{2}$ is the smallest island in The Canaries archipelago. Electrically speaking it has the lowest peak demand (maximum historical record of 8.6 MW) and annual energy demand (46.6 GWh). Secondly since the commissioning of the CHE, in June-14, the total wind-power installed capacity becomes 11.5 MW, almost 1.5 times the historical peak demand or 3 times the typical off-peak demand.
To avoid the adverse effects of non-controllable generation, as wind-power, new tools for the system operator are absolutely necessary. In one hand, to storage the excess of renewable generation, otherwise wasted due to the island demand profile and, in other hand, to contribute to the system regulation and keep control variables, as the frequency, inside security margins.

With this purpose in mind El Hierro power system counts with CHE storage hydro facility. CHE is a unique plant composed by a wind farm linked to a pumped hydro storage system, designed to feed the island demand with wind-power when available and store the excess of renewable generation by means of water moved to an upper reservoir. This water will be released to generate electricity on demand when necessary.

This, a priori, simple working process, hides a complex reality due to the high number of variables that take into account in the scheduling plan of the different system units (hydro turbines, pumps and diesel generators). One of the main issues is to face the unpredictability, in the daily term, of the wind-power generation and manage the reservoirs capacity states to be, in real time, in the best scenario to face the instantaneous wind-power variability and demand needs. Finally, other important issue is to accomplish the previous task in a way that minimizes the electrical power generation cost of the whole system.

This paper describes the main issues and solutions that have been implemented over the time, a set of improvements that have paved the way to a continuous increase of RES penetration in El Hierro Island.

\section{Experience and operation methodology}

Since CHE fully start-up in July-15 RES integration has continuously increased in El Hierro system. As shown ( Fig. 1), annual demand covered with RES has been continuously increasing, from $2.32 \%$ in 2014 to $56.5 \%$ in 2018. 


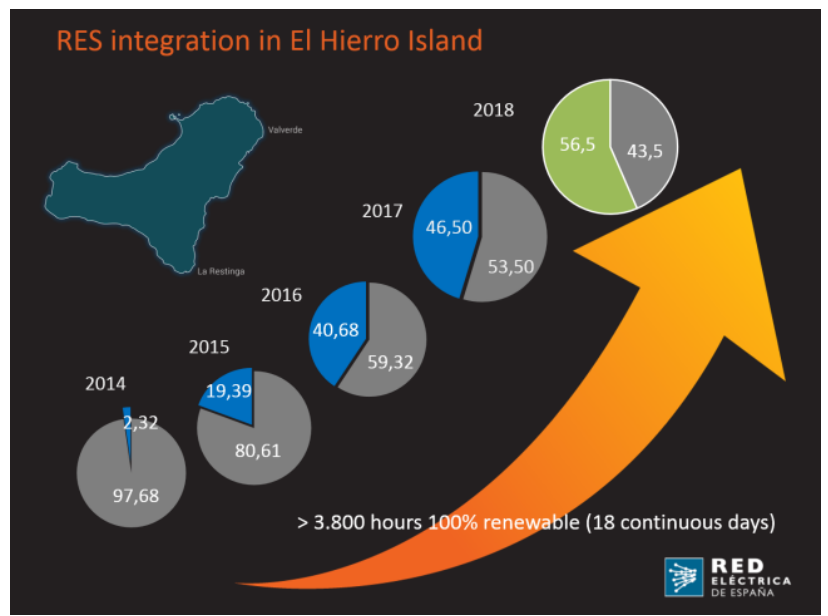

Fig. 1. RES integration in El Hierro Island over time

The reason for this increase comes from different factors, such as set up and optimization of different elements of CHE or continuous improvement of the operation process. In addition to this, we have to take into account the wind conditions (wind resource) and the annual demand behaviour (electrical consumption).

Wind resource and electrical consumption, are noncontrollable and experience proves they are difficult to forecast in small, not interconnected power systems [1]. The following (Fig. 2) and (Fig. 3) show the monthly wind-power generation and demand since 2016.

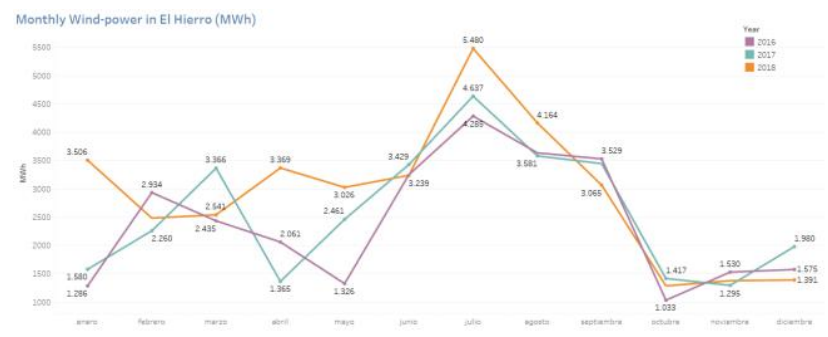

Fig. 2. Monthly wind-power in El Hierro

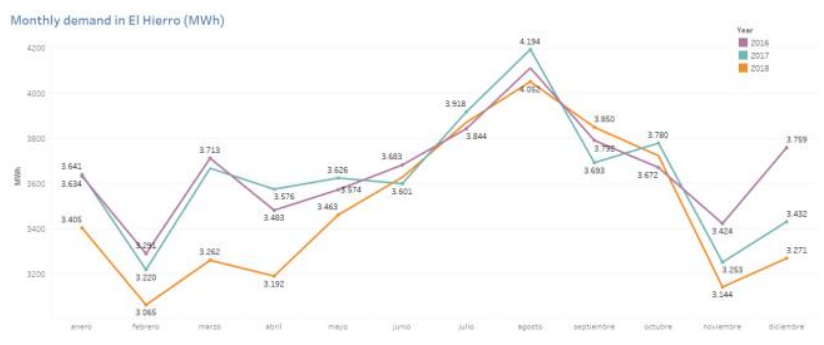

Fig. 3 Monthly demand in El Hierro

Regarding the set up and optimization of elements of CHE, the most important achievement has been the changes made in hydro-turbines' PID governors [2] aimed at enhancing their response. The fine adjustment was made at the end of Nov-17 and, as a result, the units have much better response and some stability problems of the system were solved. This PID adjustment has allowed to reduce the overall time with system frequency outside security margins $( \pm 250 \mathrm{mHz})$. (Fig. 4) shows the evolution of frequency deviation since 2014 (previous CHE commissioning) until 2018. Beginning of July-15, with CHE fully operational, the frequency deviations increase in both, time exceeding security margins and magnitude (number of deviation over $\pm 600 \mathrm{mHz}$ ). After Nov-17 there was a reduction in both number and magnitude of frequency deviations. Note that, even before $\mathrm{CHE}$, frequency deviations in El Hierro were very high, if compared with large interconnected power systems. The reason for that is the high variability of instantaneous demand (variable island consumption).

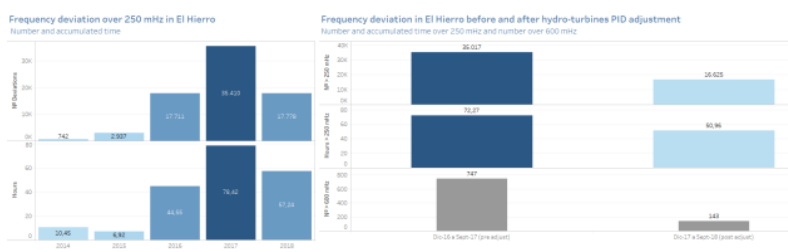

Fig. 4. Frequency deviation evolution in El Hierro

This improvement in the system stability has led to a substantial reduction in the number of under-frequency pump units shedding. The shedding has had a reduction of $93 \%$.

Finally, regarding the continuous improvement of the operation methodology, REE, playing its role as El Hierro's system operator, tries to maximize the renewable generation while keeping safety, security supply and minimum cost for the whole system. With these concepts in mind, a period of time was necessary to evaluate the precise behaviour of the plant and its individual elements in all kind of conditions, and the affection to the whole system in a wide range of operation scenarios. This approach allowed to learn, acquire experience, and analyse and apply all the necessary improvements to bring the system to its best performance, guaranteeing the security system since the commissioning of the plant. There have been no load shedding events in El Hierro derived from wind variability and its integration into the system, which proves that the massive RES integration is possible with flexible tools for power system operation.

On real time operation, to maximize renewable generation, instantaneous grid demand is covered with as much wind-power generation as possible, without compromising system safety. In other words, maximize power to grid versus power to pumping. The reason for this is the round-trip energy efficiency. Wind-power directly integrated to grid will not suffer the losses of pump-hydro cycle.

The amount of wind-power directly integrated to grid depends on the demand and the capacity of the synchronous generators (hydro-turbines and thermal units) to respond to instantaneous variability in windresource. Until the end of 2017 the hydro-turbines response was an important limitation. (Fig 5) shows how much wind-power was directly integrated to grid demand and how much was used to pump water from lower to upper reservoir. In round numbers wind-to-grid has increased from $28 \%$ in 2016 to $47 \%$ in 2018. 
Annual wind-power generation in El Hierro (MWh)

Clear green wind-to-grid and dark green wind-to-pumping.

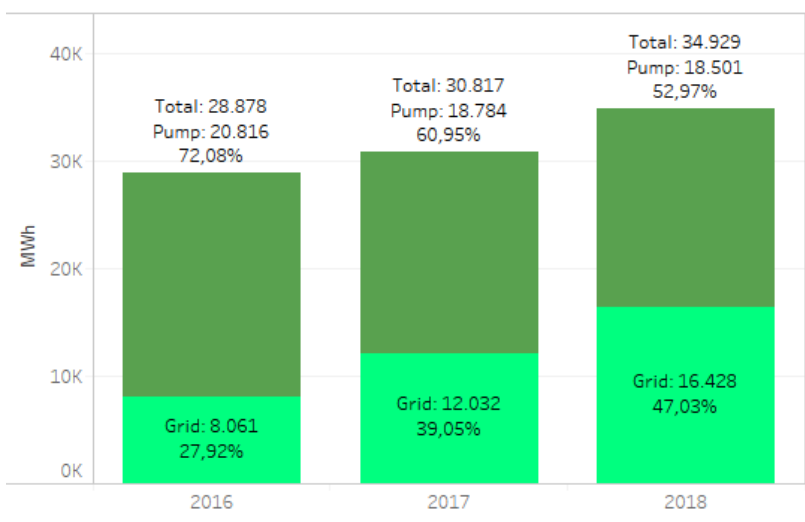

Fig. 5. Wind-to-grid and wind-to-pumping in El Hierro

Trying to maximize wind-to-grid has an important drawback: the synchronous generation units must run in power values far from nominal and therefore their efficiency is lower.

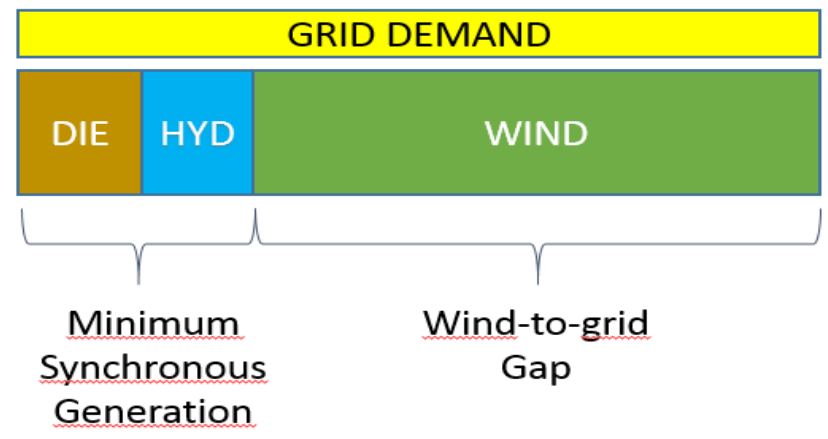

Fig. 6. Maximize wind-to-grid

For the thermal units (diesel generators) running far from nominal power values implies a higher economical cost and, also, higher $\mathrm{CO}_{2}$ emissions per MWh. For hydroturbines units running far from nominal power has, also, an impact in its efficiency. A hydro-turbine running on this conditions requires more water (from de upper reservoir) to deliver the same energy, and therefore contributes to decrease the overall efficiency of the pump hydro cycle.

REE has developed advanced unit commitment and optimal economic dispatch applications to find the best power schedule for the system generation units in different time frames (2 weeks, 1 week, 1 hour) [3]. These tools manage the available water according to an analysis on the wind forecast, among other variables.

As a consequence of both, the power schedule and the real time operation, which tends to maximize wind-togrid, the efficiency of pump-hydro cycle has been affected, suffering a decrease of some points since 2016 .

Despite this fact, the overall wind-power utilization, that means, the amount of wind-to-grid plus hydro generation (always to grid demand) has increased since 2016.
The better wind-power utilization, together with the annual demand decrease, has allowed to reach the record value of $56.5 \%$ renewable generation in 2018. As a reference, non-comparable isolated power system has been found worldwide showing better results in terms of non-controllable renewable generation integration. Fig. 7) shows monthly renewable generation in El Hierro since 2016.

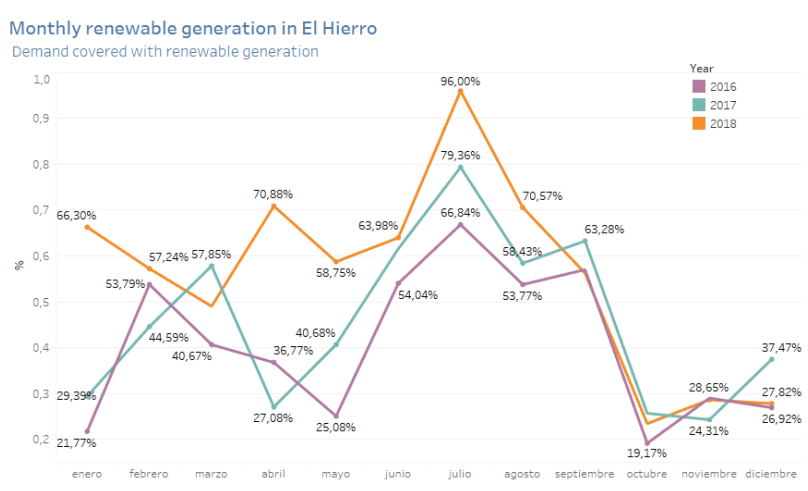

Fig. 7. Demand covered with renewable generation in El Hierro

\section{Ongoing improvements and future steps}

Despite all the achievement accomplished in the past years, there is margin for improvement in annual renewable generation in the future. These improvements can be classified in three different categories.

First of all, those that can be done over existing elements with none, or minimal, structural changes of the initial project, such as:

1) Wind farm generation improvement

2) Synchronous condenser set up and optimization

3) Hydro-turbine units efficiency improvement

Those that need an important structural change of the initial project.

1) Increase renewable installed capacity (evaluation of the more suitable technology, wind/solar/others)

2) Increase of pumping capacity (according to new renewable capacity)

3) Increase of lower reservoir capacity (according to new pumping capacity)

4) New energy storage facility

And finally, there is one feasible change that doesn't affect $\mathrm{CHE}$ project itself but can contribute remarkably to renewable integration.

1) Island demand smart controller (adjustment of island's consumption to renewable generation)

Anyway, the expected benefits potentially achieved with non-structural changes is quite low. Thus there is little room for improvement in terms of annual renewable integration unless structural changes of $\mathrm{CHE}$ project are 
accomplished. That will suppose a huge step forward in renewable integration in El Hierro Island. Actions in this direction are out of the scope of the TSO role.

All improvements that have been identified over existing elements are, at least, in study.

\section{A. Wind farm generation improvement}

Operation experience of CHE has demonstrated that the wind farm offers a good performance when the winds direction blows from NNE, which is the usual direction of the Trade winds. In those periods in which the influence of the Trade winds decline, and the wind direction changes, the wind farm turbines may suffer from turbulence, leading to a reduction in wind production due to security controls that act to prevent machine damage. In these occasions, even with enough wind speed, only the head-board wind turbine (the first one faced to the wind) contributes to the final windpower generation.

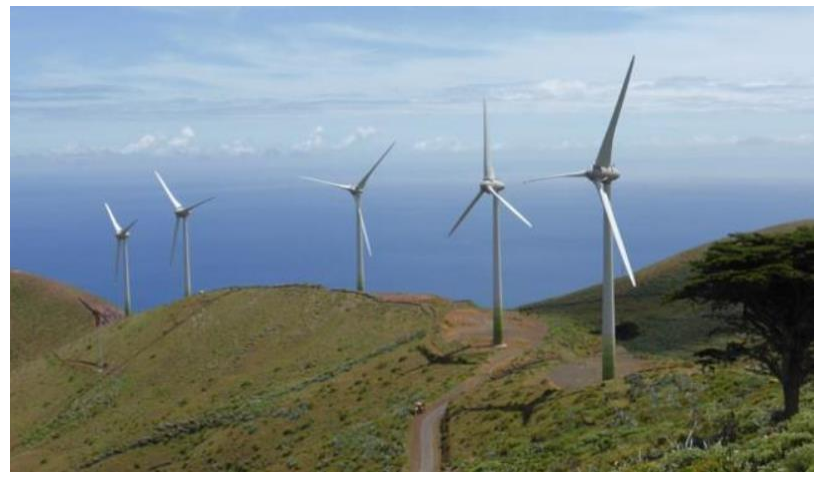

Fig. 8. Wind turbines arrangement

REE and Gorona del Viento, alongside with the wind farm manufacturer, are studying the possibility of implementing a specific wind farm control to improve this behaviour.

\section{B. Synchronous condenser set up and optimization}

From the ends of May-18 REE programmes, for evaluation, one hydro-turbine of $\mathrm{CHE}$ in synchronous condenser mode [6]. As long as there is a wind level that could cause stability problems, due to its variation, a hydro-turbine is added to the usual power dispatch in synchronous condenser mode.

The initial analyses indicate an improvement in the inertial response of the system with the support of a hidro-turbine in synchronous condenser mode. REE is working in collaboration with $\mathrm{CHE}$ to establish the best adjustment parameters that allow a more balanced inertial and primary response.

\section{Hydro-turbine units efficiency improvement}

A refurbishment of the CHE plant conduits might get rid of the extra refrigeration water consumption of hydro- turbines in synchronous condenser mode. This will allow them to run in a 'non-flow' mode as long as there is another turbine operating in normal mode. The idea is to use the water from the output of the unit running in normal operation for refrigeration purposes of every turbine in synchronous condenser mode. This would avoid the consumption associated with the water from the upper reservoir for refrigeration, consumption that will be multiplied by the number of units dispatched in synchronous condenser mode.

One of the possibilities to enhance turbine efficiency and, as a result, the overall system roundtrip efficiency, is to make then operate at their optimum charge. A way of accomplishing this is to change the units dispatching in a way that replaces turbines in normal operating mode with turbines operating as synchronous condensers. This will negatively affect system stability but, on the other hand, will allow to raise the generation level of the remaining turbine units, therefore enhancing their efficiency. This solution is particularly useful in low demand scenarios, i.e., daily demand valleys.

\section{Conclusion}

There are no references worldwide on managing power systems in a scenario like El Hierro: a wind farm tied to a pumped storage hydro system whose total installed capacity doubles the island peak demand. This makes the experience and results more valuable.

The experience have been highly positive since the starts of operations, back in the summer of 2015. Since then, a great knowledge have been gathered both from the daily operation tasks of the plant, as well as from the constant and collaborative dialog with CHE. The evolution in annual renewable integration in El Hierro power system since 2015 is:

\begin{tabular}{|c|c|}
\hline YEAR & RES integration \% \\
\hline 2015 & 19,4 \\
\hline 2016 & 40,7 \\
\hline 2017 & 46,4 \\
\hline 2018 & 56,5 \\
\hline
\end{tabular}

On top of the already accomplished modifications and improvements, there is still a certain number of actions that are currently under study or implementation, which are expected to contribute to a further increase in renewable integration.

Finally, a set of structural changes are proposed. Those modifications will be necessary to be able to make an increase in renewable penetration, as it has been identified that, in today's scenario, the renewable integration capacity of the overall system is reaching its limits. 


\section{Acknowledgement}

Special thanks to Alberto Castañeda Quintero (Gorona del Viento, acastaneda@goronadelviento.es) for his kind collaboration.

\section{References}

[1] K.D. Orwig, M.L. Ahlstrom, V. Banunarayanan, J. Sharp, J.M. Wilczak, J.F. Freedman, S.E. Haupt, J. Cline, O. Bartholomy, H.F. Hamann, B.M. Hodge, C.Finley, D. Nakafuji, J.L. Peterson, D. Maggio, M. Marquis, "Recent Trends in Variable Generation Forecasting and Its Value to the Power System", in Proc. IEEE TRANSACTIONS ON SUSTAINABLE ENERGY 2015.

[2] A. Marrero, E.J. Medina, J.M. de León, 2018, "Gorona del Viento Wind-Hydro Power Plant Results, Improvement Actuations and Next Steps", in Proc. 3rd International Hybrid Power System Workshop 2018.

[3] M. Pezic, V. Moray, "Unit Commitment in Fully Renewable Hydro-Wind Energy System", 2013.

[4] P. Tielens, D. Van Hertem, "Grid Inertia and Frequency Control in Power Systems with High Penetration of Renewables", in Proc. Young Researchers Symposium in Electrical Power Engineering, 2012.

[5] N. Taveira, J. Palomares, E. Quitmann, "The Hybrid Power Plant in El Hierro Island: Facts and Challenges from the Wind Farm Perspective", in Proc. 3rd International Hybrid Power System Workshop 2018.

[6] C.A. Platero, C. Nicolet, J.A. Sánchez, B. Kawkabani, "Increasing wind power penetration in autonomous power systems through no-flow operation of Pelton turbines", , in Proc. Renewable Energy 2014.

[7] J.I. Sarasúa, G. Martínez-Lucas, C.A. Platero, J.A. Sánchez-Fernández, "Dual Frequency Regulation in Pumping Mode in a Wind-Hydro Isolated System" in Proc. Energies 2018. 